\title{
El derecho en la modernidad: crítica desde la «exterioridad» latinoamericana
}

\author{
Por Alanís de la Vega
}

\section{Introducción}

Para Boaventura de Sousa de Santos, tres han sido las grandes promesas de la modernidad las cuales no se han cumplido o han traído consecuencias no deseables, a saber, la promesa de la igualdad, la promesa de la libertad y la promesa de la dominación de la naturaleza. La igualdad se ve incumplida por la alta marginalidad existente en los países periféricos o los sectores marginados del primer mundo; la libertad ha sido coartada por las limitaciones materiales ${ }^{1}$ que impiden el libre desarrollo de las personas en comunidad; y el dominio de la naturaleza se realizó de forma perversa, trayendo como consecuencia una crisis ecológica que amenaza al bien común de la humanidad ${ }^{2}$. Es así, que Boaventura de Sousa considera que la postura de defender a la modernidad conduce a un laberinto sin salida, de ahí, que lanza una tajante afirmación: "estamos enfrentando diversos problemas modernos para los cuales no existen soluciones modernas" (Boaventura, De Sousa Santos, 2005).

Lo anterior, nos obliga a pensar a la modernidad desde otro horizonte epistemológico, uno que responda a la realidad material e histórica de los pueblos periféricos y en específico de los pueblos latinoamericanos para la construcción de categorías de análisis coherentes con esta realidad. El derecho, no está exento de construirse desde "ese" otro horizonte epistemológico, pues, en la actualidad está sustentado en el pensamiento moderno (como veremos más adelante) siendo el derecho en general hoy en día, un instrumento inservible para la protección de las

1 En Salamanca, por ejemplo, encontramos un listado de necesidades "materiales" que los pueblos requieren para poder producir, reproducir y desarrollar su vida, las cuales clasifica en tres tipos: Necesidades de Comunicación material; Necesidades de libertad material y Necesidades de verdad material. A cada uno de los tipos corresponde una serie de necesidades (Véase, Salamanca Serrano, 2011: 362-429).

2 Para el desarrollo de la vida económica en los países centrales, se requiere la explotación tanto laboral y ecológica de los países periféricos, trayendo como consecuencia una "deuda ecológica" con estos y la pauperización de los niveles de vida de sus habitantes. El concepto de "deuda ecológica" lo tomamos del sociólogo belga François Hourtart, el cual consiste en la deuda que adquieren los países del norte frente a los países del sur por las externalidades (daños a la naturaleza e injusticias sociales) como consecuencia de la explotación sistemática que hacen de sus recursos naturales. Para conocer más sobre la crisis ecológica y del bien común de la humanidad (véase, Houtart, François, 2015) 
mayorías en estado de indefensión y que son víctimas del sistema, llámense pobres, campesinos, indígenas, migrantes, obreros, etc.

Optamos por construir "ese" otro horizonte epistemológico desde la exterioridad, pero, desde la exterioridad latinoamericana, la cual permite re-pensar a la modernidad de forma crítica, descubriéndola como una reproducción de la historia particular europea, colocando a Europa como el fin y el centro de la historia mundial (Dussel, 2004).

En este trabajo se pretende presentar una crítica a la modernidad y su influencia en el derecho desde la categoría leviniasiana de exterioridad, misma que fue retomada por Dussel, la cual ubicó en el contexto histórico-material del Tercer Mundo. Lo anterior, permitirá pensar al derecho desde la exterioridad, desde un locus epistemológico adecuado a la realidad latinoamericana, desde el explotado y/u oprimido de nuestros pueblos (sujeto emergente de la liberación).

Pensar al derecho desde la exterioridad, posibilita ir más allá del aparato teóricojurídico de la modernidad cuya fuente es el pensamiento liberal, permitiéndonos enfrentar a los problemas de la modernidad desde un pensamiento liberador auténticamente latinoamericano que ha de encontrarse en la experiencia histórica y en el imaginario utópico del sincretismo cultural proveniente del mundo, negro, indígena y del pueblo oprimido. Cabe aclarar, que no se trata de negar toda forma teórica proveniente de occidente, tampoco las prácticas emancipadoras de la modernidad, sino, coincidiendo con Antonio Wolkmer, "de intentar construir un mundo de vida basado en nuevos paradigmas de legitimidad y racionalización" (Wolkmer, 2006:107). Pensar al derecho desde la exterioridad, pues, compromete a éste con los procesos de liberación y con el pleno reconocimiento de la alteridad del Otro, de la justicia y del derecho a la vida con dignidad.

Partiremos entonces, del estudio a grosso modo de la modernidad en base en los teóricos modernos - perspectiva intra-sistémica- los cuales, si bien admiten algunas consecuencias negativas de la modernidad, lo que se busca es solucionarlas con horizontes categoriales modernos, cayendo en la afirmación anterior de Boaventura de Sousa. Enseguida, daremos mayor énfasis al estudio de la modernidad desde la exterioridad, analizando las diversas propuestas encabezadas por Enrique Dussel, Walter Mignolo, Boaventura de Sousa, Santiago Castro Gómez y Aníbal Quijano, encontrando las semejanzas entre éstas, pero también distinguiéndolas. A partir de aquí, delimitaremos nuestra crítica a la modernidad con el marco categorial propuesto por Enrique Dussel, tomando a la categoría de exterioridad como parte fundamental de nuestra crítica.

Después, en el segundo punto, siguiendo con el marco categorial de Dussel, nos adentraremos al estudio histórico de la modernidad, el cual se traduce en dos etapas y se distinguen por el dominio de una civilización o región como centro geopolítico del 
sistema -mundo, a saber, estas etapas son: "la temprana modernidad" o "primera modernidad" y la "hegemonía mundial de Europa" o "segunda modernidad". Esto, permite entender mejor la evolución histórica e influencia occidental sobre el derecho latinoamericano, así como la génesis del eurocentrismo el cual llega hasta nuestros días.

En el tercer punto, presentaremos cómo la filosofía de la modernidad ha contribuido a la constitución y reproducción de la universalidad abstracta y a la descorporalización del sujeto epistémico desde donde se enuncia la realidad. Entender al universalismo abstracto y su repercusión en el mundo jurídico, se vuelve de suma importancia para poder ajustar el derecho a la realidad material latinoamericana y visibilizar al sujeto de su enunciación.

En el cuarto punto, analizaremos la evolución del derecho en la modernidad, en base al criterio histórico enunciado en el segundo punto, tomando en cuenta que el derecho por estar inserto en la modernidad estará constituido por universalismo abstracto y el eurocentrismo.

Finalmente, expondremos la categoría de exterioridad y la aplicaremos al derecho, por consiguiente, explicaremos qué significa pensar al derecho desde la exterioridad.

\section{Perspectivas de la Modernidad}

Para comprender a la modernidad y visibilizar sus consecuencias es necesario empezar con la discusión de las tendencias dominantes en su estudio, las cuales podríamos clasificar desde dos locus epistemológicos, las «perspectivas intramodernas» en donde la modernidad puede ser explicada totalmente por referencia a factores internos de Europa y las perspectivas que parten de la exterioridad, es decir, desde las locaciones periféricas las cuales permiten re-pensarla.

Las "perspectivas intra-modernas» son encontradas tanto en pensadores como Habermas, Giddens, Taylor, Touraine, Lyotard, Rorty, así como en Kant, Hegel y en la Escuela de Frankfurt, siendo Habermas y Giddens particularmente influyentes, generando diversos estudios respecto a la modernidad y la globalización. Desde esta perspectiva, la modernidad puede ser caracterizada de la siguiente manera (Véase, Arturo, Escobar:51-86):

Histórica: Centrando los orígenes temporales y espaciales de la modernidad en la Europa del siglo XVII, especialmente en Francia, Alemania e Inglaterra, alrededor de los procesos de la Reforma, la Ilustración y la Revolución Francesa. Estos procesos se cristalizaron al final del siglo XVIII y se consolidaron con la Revolución Industrial.

Sociológica: La modernidad se caracteriza por el nacimiento de determinadas instituciones, por ejemplo, el Estado- nación y en las últimas décadas por el "desmembramiento de la vida social del contexto local y sus crecientes 
determinaciones por fuerzas trans-locales; y el distanciamiento espacio- tiempo o la separación de espacio y lugar, desde relaciones entre "ausentes otros» que devienen más importantes que la interacción cara a cara” (Ibidem).

Cultural: La modernidad se caracteriza por lo que Habermas describe como una creciente "racionalización del mundo de la vida", que le es acompañada por la universalización e individuación. La modernidad introduce un orden basado en la razón (racionalismo) en el individuo (individualismo), el conocimiento experto y los mecanismos administrativos ligados al Estado.

Filosófica: La modernidad parte de la emergencia del hombre como fundamento de todo el conocimiento y orden en el mundo, dejando a un lado lo divino, propio de la edad media, y tratando de comprender la naturaleza y el dominio de ésta. Para Vattimo, "la modernidad es caracterizada por la idea de historia y su corolario, progreso y superación”(Ídem). Vattimo enfatiza la lógica del desarrollo, es decir, la creencia del progreso infinito y civilizador, como crucial para la fundación filosófica del orden moderno.

Frente a esta forma de entender a la modernidad, surge en contrapartida las perspectivas que la piensan desde la exterioridad, quienes ven a la modernidad como reproducción de la historia particular europea, colocando a "Europa como el fin y el centro de la historia mundial".

Diversos pensadores como Walter Mignolo, Aníbal Quijano, Enrique Dussel, Santiago Castro Gómez, Boaventura de Sousa Santos, entre otros, re-piensan el proyecto de la modernidad con base en lo siguiente (Escobar, 2003:60-61):

Localizan el origen de la modernidad en la Conquista de América y el control del Atlántico después de 1492, frente a la ilustración o el final del siglo XVIII, como la historia universal europea lo enuncia;

Pensar al colonialismo y al desarrollo del sistema mundial capitalista como constitutivos de la modernidad. Esto incluye una determinación de no pasar por alto la economía y sus concomitantes formas de explotación;

Entender a la modernidad como un fenómeno intra-europeo;

La identificación de la dominación de otros afuera del centro europeo como una necesaria dimensión de la modernidad, con la concomitante subalternización del conocimiento y las culturas de esos otros grupos;

Surge una concepción del Eurocentrismo, como la forma de conocimiento de la modernidad el cual consiste en la representación hegemónica y modo de conocimiento que arguye su propia universalidad y que descansa en "una confusión entre una universalidad abstracta y el mundo concreto derivado de la posición europea como centro" (Dussel, 2000). 
Tras esta serie de posiciones, emergen nociones alternativas de la propuesta eurocéntrica, que han sido desarrolladas por los pensadores antes mencionados (Escobar, 2003):

Descentramiento de la modernidad de sus alegados orígenes europeos, incluyendo un descrédito de la secuencia lineal enlazando a Grecia, Roma, la cristiandad y la Europa moderna;

Una nueva concepción espacial y temporal de la modernidad en términos del papel fundacional de España y Portugal -la así llamada "primera modernidad" iniciada con la Conquista- y su continuación en la Europa del Norte con la Revolución Industrial y la Ilustración -la "segunda modernidad", en términos de Dussel-; la segunda modernidad no remplaza la primera, sino que se le superpone hasta el presente;

Un énfasis en la periferialización de todas las otras regiones del mundo por esta «Europa moderna», con Latinoamérica como el inicial «otro lado» de la modernidad el dominado y encubierto-;

Una relectura del «mito de la modernidad», no en términos de cuestionar el potencial emancipatorio de la razón moderna, sino de la imputación de superioridad de la civilización europea articulada con el supuesto de que el desarrollo europeo debe ser unilateralmente seguido por toda otra cultura, por la fuerza si es necesario -lo que Dussel denomina «la falacia desarrollista».

Finalizamos este punto con las siguientes conclusiones, partiendo en encontrar las semejanzas y distinciones que caracterizan la crítica a la modernidad desde la exterioridad. Como semejanza los diversos autores ${ }^{3}$ - ya antes mencionados- coinciden en que es necesario pensar a la modernidad desde la exterioridad, es decir, desde los países periféricos para descubrir que el "mito de la modernidad" no es más que la reproducción de la historia local europea en un espacio y tiempo determinados, colocando a "Europa como el fin y el centro de la historia mundial". Además, coinciden también que el desarrollo del capitalismo y el encubrimiento de la exterioridad son momentos constitutivos de la modernidad, trayendo como consecuencia la subalternización de los otros saberes y el despliegue de una forma de dominación y explotación basada en la idea de la raza y expropiación de los medios de producción de los nativos americanos. Es en este punto en donde surgen las distinciones, ya que dichos autores enfatizan distintos factores en la producción y funcionamiento de la modernidad, así como diversas propuestas para re-pensarla.

3 Entre los autores encontramos a Walter Mignolo, Aníbal Quijano, Enrique Dussel, Santiago Castro Gómez, Boaventura de Sousa Santos. 
Por ejemplo, para Quijano la modernidad es re-pensada desde la colonialidad ${ }^{4}$, cuyo proceso clave en su constitución es la clasificación colonial y dominación en términos raciales- la colonialidad del poder- y para su superación es necesario un pensamiento decolonial que permita llevar a cabo un "giro decolonial" o "decolonizador". En cambio, para Dussel si bien coincide con Quijano en el despliegue de la colonialidad del poder y entiende el "giro decolonial" como un "giro epistémico", éste opta en criticar a la modernidad desde la Filosofía de la Liberación, cuyo método analéctico permitirá partir del Otro -que es trascendental ya que está más allá de mi mundo afirmando su vida, la cual es negada en el sistema-modernocapitalista, para negar la negación y liberarlo, haciendo posible la reproducción y producción de su vida. Para Boaventura de Sousa, inscribe su análisis partiendo de las "epistemologías del sur", ya que, para él, existe una crisis muy profunda de la teoría crítica eurocéntrica, y esa crisis "se manifiesta en cuatro grandes áreas de interés: 1) preguntas fuertes y respuestas débiles, 2) contradicción entre medidas urgentes y cambio civilizatorio, 3) pérdida de los sustantivos, y 4) relación fantasmal entre la teoría y la práctica" ${ }^{6}$. Además, para Boaventura, la modernidad está caracterizada por

4 Para Aníbal Quijano, "la colonialidad es uno de los elementos constitutivos y específicos del patrón mundial de poder capitalista. Se funda en la imposición de una clasificación racial / étnica de la población del mundo como piedra angular de dicho patrón de poder, y opera en cada uno de los planos, ámbitos y dimensiones, materiales y subjetivas, de la existencia cotidiana y a escala" (Véase, Quijano, Aníbal, 2014). Además, Quijano distingue entre colonialismo y colonialidad, para él, este último se refiere estrictamente a una estructura de dominación y explotación, donde el control de la autoridad política, de los recursos de producción y del trabajo de una población determinada lo detenta otra de diferente identidad, y cuyas sedes centrales están, además, en otra jurisdicción territorial. Pero no siempre, ni necesariamente, implica relaciones racistas de poder. El colonialismo es, obviamente, más antiguo, en tanto que la colonialidad ha probado ser, en los últimos quinientos años, más profunda y duradera que el colonialismo. Pero sin duda fue engendrada dentro de éste y, más aún, sin él no habría podido ser impuesta en la intersubjetividad del mundo, de modo tan enraizado y prolongado." (ídem).

5 No hay un término definitivo, algunos autores utilizan "Giro decolonial" o "Giro decolonizador", no obstante, se refieren "a la transformación interior de la subjetividad colonizada, o, dicho de otra manera, a la recuperación y afirmación radical de la humanidad de sujetos a quienes se les ha negado su humanidad sistemáticamente. Esta afirmación es radical, y no sólo relativa, cuando abandona la idea normativa de humanidad y se aventura a ofrecer una concepción de lo humano a partir de la misma experiencia de sobrevivencia creativa y transformación frente a la modernidad/colonialidad. "Todo movimiento, toda rebelión, todo pensamiento que ha intentado restaurar la humanidad de los deshumanizados sin tomar la humanidad del colonizador moderno como la norma y promoviendo la generosidad y la acción conjunta entre los deshumanizados mismos y sus aliados pertenecen al pensamiento descolonizador y representan puestas en práctica diversas del giro decolonial"(Véase, Maldonado Torres, 2009).

6 Para Boaventura de Sousa, las cuatro grandes áreas de interés se resumen de la forma siguiente: La primera concierne al hecho de que vivimos en un tiempo de preguntas fuertes y respuestas débiles: Cada vez somos más conscientes de que nuestros horizontes de posibilidades están más limitados, de que quizás es necesario un cambio de civilización, sobre todo en la gestión ambiental, por ejemplo, de la cual ya no se habla en Europa por la crisis financiera, uno de los 
un equilibrio entre regulación y emancipación, convertidos en los dos pilares sobre los cuales se sostiene la transformación radical de la sociedad pre-moderna. Walter Mignolo también partirá de una epistemología pensada desde la periferia y desarrolla su crítica a la modernidad a partir del "pensamiento de frontera", el tipo de pensamiento que introduce la subalternización del conocimiento y la racionalidad. "El proyecto de Mignolo es conducir una genealogía de las historias locales dirigidas a designios globales, posibilitando así otros designios desde otras historias locales que emergen del pensamiento de frontera y la diferencia colonial". Tanto Mignolo como Santiago Castro Gómez se inscriben dentro del pensamiento que se ha denominado "decolonial".

\section{La historia de la modernidad: "temprana modernidad" y la "hegemonía mundial europea"}

Para Dussel la historia de la modernidad se traduce en dos etapas, las cuales se distinguen por el dominio de una civilización o región como centro geopolítico del sistema -mundo. ${ }^{7}$ Por lo anterior Dussel identifica dos momentos de la modernidad:

objetivos de la cual es precisamente acallar las aspiraciones ambientales; La segunda área hace referencia a las grandes contradicciones que existen en la actualidad: hace referencia a las grandes contradicciones que existen en la actualidad, y que los más jóvenes pueden sentir muy bien. Por un lado, vemos cómo las condiciones de vida actuales y las reuniones inter-gubernamentales por el cambio climático de Copenhague y de Cancún, por ejemplo, nos dan cuenta de ello traen consigo un sentimiento de urgencia por cambiar las cosas. Por el otro, y en contradicción, nos parece que los cambios tienen que ser de civilización, de largo plazo, ya que la situación actual no se resuelve en tres años; La tercera área es tenaz y tiene relación con la pérdida de los sustantivos: Durante mucho tiempo la teoría crítica tuvo palabras que sólo usaban los teóricos críticos, los pensadores de las alternativas. Hablamos de palabras como: socialismo, comunismo, luchas de clases, reificación, fetichismo de las mercancías, alienación; eran palabras de un pensamiento crítico. En los últimos treinta años, la teoría crítica ha ido perdiendo todos los sustantivos hasta quedarse ahora con los adjetivos. Aquí estoy hablando de mis propios conceptos, y estoy haciendo autocrítica; y la cuarta y última relación fantasmal entre la teoría y la práctica: la teoría crítica ha propuesto una serie de alternativas con sujetos históricos conocidos, pero realmente quienes han producido cambios progresistas, en los tiempos más recientes, han sido precisamente grupos sociales totalmente invisibles para la teoría crítica eurocéntrica, esto es, las mujeres, los indígenas, los campesinos, los gays y lesbianas, los desempleados. Así, se ha negado el proceso histórico a un conjunto de gente, de actores que, además, no viven en las grandes ciudades urbanas, como pensábamos, siguiendo a Karl Marx. Es por eso que se produce una relación fantasmal entre la teoría y la práctica, ya que la teoría no habla con la práctica y la práctica no habla con la teoría. (Boaventura, De Sousa Santos, 2011:14-16).

7 Dussel entiende por "Sistema-mundo" al "Sistema interregional", entendiendo por región una alta cultura o civilización. A partir del sistema-mundo se interpretan los entes y el Otro partiendo de la totalidad de mis experiencias. Más adelante hablaremos del Sistema- mundo que el Doctor Dussel explicita en su Filosofía de la Liberación. 
"la tempana modernidad" o "primera modernidad" y la "Hegemonía mundial de Europa" o "segunda modernidad".

En la "temprana modernidad", la modernidad es hispánica, humanista, renacentista, ligada todavía al antiguo sistema interregional de la cristiandad mediterránea y musulmana. A partir de este momento se concebirá la gestación del nuevo sistema-mundo, desde el paradigma antiguo del sistema interregional. Con el descubrimiento de América, España y Portugal despliegan su sistema- mundo a las nuevas tierras, siendo "la primera región de Europa que tiene la originaria experiencia de constituir al Otro como dominado, bajo el control del conquistador" (Dussel, 1994:17). Es en este momento cuando Europa se abre al mundo, no obstante, debemos de tener conciencia que esa Europa aún era periférica en referencia al espacio económico y cultural continental asiático.

En esta época se produce la colonialidad del poder, es decir, "el poder europeo bajo el peso de Oriente tiene por su parte su periferia colonial naciente" (Dussel, 2004): América Latina y África. Los indígenas americanos reciben el impacto de la primera globalización (conquista), se instaura el mito de la superioridad europea, así como el racismo, la explotación económica y dominación política -la colonialidad del poderconstruyéndose perfectamente el "mito de la modernidad".

Dicho mito consistirá en afirmar la superioridad cultural-europea/españolacomo la más desarrollada y se determina a la otra cultura - nativas americanas- como inferior, ruda, bárbara, por consiguiente, la dominación y explotación de ésta es necesaria para el bien del bárbaro que se civiliza, que se desarrolla o moderniza. Dussel nos brinda mayor claridad para entender el "mito de la modernidad":

En esto consiste «mito de la modernidad», en un victimar al inocente (al Otro) declarándolo causa culpable de su propia victimización, y atribuyéndose el sujeto moderno plena inocencia con respecto al acto victimario. Por último, el sufrimiento del conquistado (colonizado, subdesarrollado) será interpretado como el sacrificio o el costo necesario de la modernización (Dussel, 1994).

Es así como "la temprana modernidad" se preguntará ante la conquista de América ¿Qué derecho tiene el europeo de ocupar, dominar, gestionar las culturas recientemente descubiertas, militarmente conquistadas y que están siendo colonizadas?(Dussel, 1998) la respuesta será objeto de una gran producción teórica filosófica, destacando a Ginés de Sepúlveda como promotor del "mito de la modernidad" y en defensa de los indios destacan la participación de Fray Bartolomé de las Casas, Fray Alonso de la Veracruz y Francisco de Vitoria entre otros. Sería el 
fraile dominico quien ante la expansión del sistema-mundo-periférico europeo sentenció que no se cuenta con el derecho y legitimidad ética alguna:

Dos maneras generales y principales han tenido los que allá han pasado, que se llaman cristianos, en extirpar y raer de la haz de la tierra aquellas miserandas naciones. La una por injustas, crueles, sangrientas y tiránicas guerras. La otra, después que han muerto todos los que podrían anhelar y suspirar o pensar la libertad, o en salir en los tormentos que padecen, como son los señores naturales y los hombres varones (porque comúnmente no dejan en las guerras a vida sino los mozos y mujeres) oprimiéndoles con la más dura y áspera servidumbre en que jamás hombres ni bestias pudieron ser puestas [...] La causa porque han muerto y destruido tantas y tales y tan infinito número de ánimas los cristianos, ha sido solamente por tener por fin último el oro y henchirse de riqueza en muy breves dias, por la insaciable codicia y ambición que han tenido(De las Casas, Bartolomé, 2016).

Cabe hacer mención, que toda la reflexión teórica y filosófica de mayor importancia de esta "temprana modernidad" ha pasado desapercibida por la llamada filosofía moderna.

Para Dussel la "temprana modernidad" europea, "la modernidad hispánica, humanista, dineraria, manufacturera y mercantil, se desarrolla solo con hegemonía sobre el atlántico, que todavía no es centro geopolítico del sistema-mundo" (Dussel,2004) -el cual los sigue siendo el mar de China en el sudeste asiático y el Indostán. Es una modernidad cuyo espacio mundial todavía es periférico respecto al mundo chino, musulmán e indostánico.

Es precisamente la caída del dominio de la región asiática dominadas por China y el Indostán, debido al efecto de la estructura china que impedía el ascenso de la burguesía que se tradujo en una crisis de política múltiple: bajos salarios y explosión demográfica- como consecuencia de la riqueza acumulada a partir de 1400 -que "la Revolución Industrial fue posible como fruto europeo articulado con un vacío" producido por el mercado chino-. "Este vacío trajo la posibilidad de ser llenado por una producción europea creciente que había ido preparándose desde finales del siglo XV" (Ibidem) debido a la extracción de mercancías provenientes de las colonias, sobre todo el oro y la plata que les servía como moneda de intercambio con el horizonte asiático. Es desde aquí, a partir de la Revolución Industrial -la cual ideológicamente se fundamenta en el fenómeno de la ilustración y el movimiento romántico- que Europa pasará a ser una "hegemonía mundial", como ya se dijo, esto fue posible gracias al "ascenso de Occidente articulado con la decadencia del Este". Dussel ubica 
en esta etapa al nacimiento de la "segunda modernidad" o "hegemonía mundial europea", que con claridad no se hubiese podido dar sin la primera o la "temprana modernidad".

Siguiendo a Dussel, la ilustración servirá para encubrir toda interpretación anterior de la antigua Europa desconectada, secundaria, periférica del mundo musulmán, chino e indostánico. Desde Hegel, Marx, Comte hasta Weber, incluyendo a Habermas, Lévinas, Foucault entre otros, el eurocentrismo brillará sin oposición. "Y dominará el mundo colonial con el «fasto de la cultura occidental», como la expresión "desde siempre" del centro más desarrollado de la humanidad" (Ibidem:217).

En Hegel, por ejemplo, se justifica la aniquilación del Otro, como un designio del espiritu europeo debido a la inferioridad de los hombres de la "cultura natural", así, la conquista de un país del Nuevo Mundo:

Se reduce a hacernos saber que se trataba de una cultura natural, que había de perecer tan pronto como el espíritu [europeo] se acercara a ella. América se ha revelado siempre y sigue revelándose impotente en lo físico como en lo espiritual. Los indígenas, desde el desembarco de los europeos, han ido pereciendo al soplo de la actividad europea. En los animales mismos se advierte igual inferioridad que en los hombres [...] Estos pueblos de débil cultura perecen cuando entran en contacto con pueblos de cultura superior y más intensa. En los Estados Unidos de Norteamérica, todos los ciudadanos son emigrantes europeos, con quienes los antiguos habitantes del país no pueden mezclarse (Robles, Fernando, 2012).

La exclusión de lo no europeo como criterio civilizador, dio a Europa dominación cultural e ideológica. "Lo no europeo terminó por desaparecer en toda consideración práctica y teórica" (Dussel, 2004). Es así como los mismos españoles y portugueses respecto de la "temprana modernidad" o los musulmanes, chinos e indostánicos respecto de su centralidad en el viejo mundo hasta el siglo XVIII, terminarán por aceptar la interpretación nord-eurocentrica ${ }^{8}$, expuesta por Hegel y reproducida por posteriores filósofos hasta la actualidad.

$8 \mathrm{La}$ interpretación nord-eurocentrica se refiere en pensar a Europa como el centro y fin de la historia universal que para Hegel ha sido desde siempre. Además, para este filósofo el desarrollo histórico y cultural de las civilizaciones se explica del Este a Oeste, siendo el Oeste Europa como el máximo desarrollo del espíritu. Todo lo anterior se sintetiza en el siguiente texto de Hegel: "El espíritu Germánico es el Espíritu del Nuevo Mundo, cuyo fin es la realización de la Verdad absoluta [...] como autodeterminación [...] infinita de la libertad, que tiene por contenido su propia forma absoluta”. (Dussel, 1998:50) 
El universalismo abstracto de la modernidad: el surgimiento del racismo epistemológico

Entender al universalismo abstracto y su repercusión en lo concreto- material, se vuelve de suma importancia para la construcción de una teoría del Derecho que responda a la realidad material de los pueblos latinoamericanos, y que supere la visión eurocéntrica que las elites intelectuales del mundo jurídico reproducen en nuestros pueblos, ya que la filosofía de la modernidad ha contribuido a la constitución y reproducción del universalismo abstracto y a la des-corporalización del sujeto epistémico desde donde se enuncia la realidad, siendo por consiguiente eurocéntrica.

Al respecto Dussel nos brinda claridad sobre el tema:

El eurocentrismo consiste exactamente en constituir como universalidad abstracta humana en general momentos de la particularidad europea [...] La cultura, civilización, la filosofía, la subjetividad etc., moderno- europeas fueron tomadas como la cultura, la civilización, la filosofía, la subjetividad etc., sin más, humano universal abstracta (Dussel, 1998:67-68).

Siguiendo a Ramón Grosfoguel el universalismo es abstracto en dos sentidos: el primero (a) en el sentido de los enunciados, ya que es un conocimiento que se abstrae de toda determinación espacio temporal y pretende ser eterno, y el segundo (b), en el sentido epistémico del sujeto de enunciación, el cual es abstraído, vaciado de cuerpo y contenido, y de su localización en la cartografía de poder mundial, es un sujeto sin rostro ni localización espacio-temporal, el de la ego-política del conocimiento que ha continuado hasta nuestros días (Grosfoguel, Ramón, 2008).

Clasificar el universalismo abstracto en estos dos sentidos nos posibilita abordar mejor los planteamientos filosóficos provenientes de los principales filósofos modernos -Descartes, Kant, Hegel y Marx-, que como se mencionó líneas arriba, han contribuido en constituir la universalidad abstracta. En este punto, sólo analizaremos a cuatro filósofos los cuales hasta el día de hoy siguen siendo de gran importancia para la construcción del pensamiento moderno, nos referimos a Descartes, Kant, Hegel y Marx.

Descartes es considerado como el fundador de la filosofía moderna, entendía lo universal como un conocimiento eterno más allá del tiempo y el espacio, es decir, equivalente a la mirada de Dios - universalismo en sentido (a) - por consiguiente, todos los atributos del "Dios cristiano" quedaron localizados en el sujeto, en el "yo". "Para poder reclamar la posibilidad de un conocimiento más allá del tiempo y el espacio, desde el ojo de Dios, era fundamental desvincular al sujeto de todo cuerpo y territorio, es decir, vaciar al sujeto de toda determinación espacial o 
temporal"(Ibidem:201)-universalismo en sentido (b) -. Por lo anterior, el dualismo en Descartes será eje fundamental de toda su filosofía. Dado que Descartes sitúa al sujeto individual como el fundamento de todo conocimiento -el lugar epistémico de enunciación-el monólogo interno del sujeto sin ninguna relación dialógica con otros seres humanos le permite hacer un reclamo de acceso a la verdad sui generis, es decir, como autogenerado, aislado de todas las relaciones sociales con otros seres humanos, por eso el sujeto cartesiano es denominado como solipsista.

Para Santiago Castro Gómez, con Descartes se inaugura la ego-política del conocimiento, dando paso a la filosofía del punto cero, "una filosofía donde el sujeto epistémico no tiene sexualidad, género, etnicidad, raza, clase, espiritualidad, lengua, ni localización epistémica en ninguna relación de poder y produce la verdad desde un monólogo interior consigo mismo sin relación con nadie fuera de sî" (Véase CastroGómez, Santiago, 2005).

En Kant, quien pretende resolver algunos de los dilemas del universalismo cartesiano, vemos la explicitación de lo eurocéntrico que en Descartes se encontraba implícito, lo anterior respecto al universalismo en sentido (b), ya que para Kant la razón trascendental solamente la tienen aquellos considerados como "hombres". Pero ¿A quiénes consideraba Kant como hombres? Si partimos de sus escritos antropológicos (Kant, Immanuel, 2004) sabremos que la razón trascendental es masculina, blanca y europea, por lo tanto "los hombres africanos, asiáticos indígenas, sur-europeos (españoles, italianos y portugueses) y todas las mujeres (incluidas las europeas) no tienen acceso a la «razón»". Kant al igual que Descartes mantiene el dualismo mente-cuerpo y el solipsismo cartesiano, si bien cuestiona el universalismo abstracto cartesiano- universalismo en sentido (a) - al limitarlo con la categoría espacio- temporalidad, afirma y explicita el eurocentrismo del universalismo en sentido (b).

Hegel en cambio, revoluciona la filosofía occidental durante las primeras tres décadas del siglo XIX, cuestionando el solipsismo y superando al dualismo. Al primero, lo supera situando al sujeto de enunciación en un contexto históricouniversal, mientras que al segundo lo supera al plantear la identidad del sujeto y el objeto. Hegel cuestionará el universalismo en el sentido (a), no obstante, continuará con ello y con el eurocentrismo ya explicitado por Kant en el universalismo de sentido (b).

Si queremos comprender el universalismo en el sentido (a) de Hegel, partamos en que, para el filósofo alemán, el movimiento del pensamiento va de lo abstracto a lo concreto. El desarrollo de las categorías corre paralelo a la historia universal, siendo ésta una expresión de la primera. "Las categorías o conceptos se deducen a partir de las mediaciones, contradicciones y negaciones del pensamiento y se mueven de universales abstractas hacia universales concretas" (Grosfoguel, Ramón, 2008). Por negación de categorías, Hegel no entiende desaparición de las mismas sino 
subsunción, es decir, que "las categorías simples se mantienen como determinaciones de las categorías más complejas". A través de ese movimiento, Hegel pretende llegar a un Saber Absoluto válido más allá de todo tiempo y espacio.

En el método dialéctico hegeliano vemos una maquinaria epistémica que va a subsumir y transformar toda alteridad y diferencia en parte de lo mismo, hasta llegar al Saber Absoluto, siendo Europa "el inicio y fin de la historia mundial" y casualmente el representante máximo será Hegel, pues para él, de ahí en adelante nada nuevo puede ser producido a nivel del pensamiento y de la historia humana.

El Saber Absoluto, afirmará el universalismo en el sentido (b) y continuará con el racismo epistemológico, ya que éste solo podrá ser alcanzado por un hombre-blancocristiano-heterosexual-europeo, y la multiplicidad de las determinaciones del Saber Absoluto son subsumidas al interior de la cosmología / filosofía occidental. Grosfoguel, sintetiza bien esta cuestión al decir que:

Nada queda fuera como alteridad en el Saber Absoluto hegeliano [...] Filosofías otras como las orientales son despreciadas y en el caso de filosofías indígenas y africanas no son dignas de ser llamadas filosofía pues el Espíritu Universal nunca pasó por allá (Ibidem:205).

Finalmente, Marx criticará el universalismo hegeliano, así como su movimiento dialéctico y pese a que le dará un giro materialista, seguirá manteniendo el universalismo en el sentido (b). Marx reconoce el movimiento de lo abstracto a lo concreto, sólo que este no es un movimiento simplemente de categorías filosóficas sino de categorías de la economía política, dichas categorías para Marx tendrán gran primacía sobre su pensamiento, además hay un movimiento anterior al elevarse de lo abstracto a lo concreto que Hegel no reconoce y Marx sí, se trata del movimiento de lo concreto hacia lo abstracto, es decir, "desde la percepción sensorial y realidad empírica situada en un momento de la evolución de la economía política y la lucha de clases hacia las categorías más abstractas" de las cuales deduce la realidad.

En este sentido, para Marx el movimiento del pensamiento en un primer momento va de lo concreto hacia lo abstracto para producir categorías simples y en segundo momento hace el retorno de lo abstracto hacia lo concreto para producir categorías complejas.

Lo que Marx mantiene en común con los filósofos anteriormente expuestos, es el universalismo en el sentido (b), ya que el sujeto epistémico desde el cual se enuncia si bien es el proletariado, no problematiza el hecho de que dicho sujeto sea europeo, masculino, heterosexual, blanco, judeo-cristiano, etc. La diversidad cosmológica y epistemológica, así como la multiplicidad de relaciones de poder sexual, de género, 
racial, espiritual, no queda incorporada ni situada epistémicamente en su pensamiento. Grosfoguel, nos da claridad respecto a este punto:

En Marx, en el universalismo epistémico de segundo tipo [sentido (b)], el sujeto de enunciación queda oculto, camuflado, escondido bajo un nuevo universal abstracto que ya no es «el hombre», «el sujeto trascendental», «el yo», sino «el proletariado»y su proyecto político universal es «el comunismo». De ahí que el proyecto comunista en el siglo XX fuera desde la izquierda otro diseño global imperial / colonial que bajo el imperio soviético intentó exportar al resto del mundo el universal abstracto del «comunismo» como «la solución» a los problemas planetarios (Ibidem:207).

Concluimos, destacando que cualquier propuesta que se construya a partir del universalismo global, es decir, del sistema-mundo hegemónico, no escapará de ser un diseño global-imperial, que seguirá reproduciendo al racismo epistemológico universalismo en sentido (b) - el cual considera inferiores a todas las epistemologías no-occidentales y encubre quién habla y desde dónde se habla en las relaciones del poder global.

\section{El Derecho en la modernidad}

Una vez delimitado nuestro aparato teórico -filosófico crítico de la modernidad, pasaremos al análisis del Derecho en base a ello, lo que nos posibilitara criticar al Derecho moderno desde la exterioridad latinoamericana.

Siguiendo las líneas antes expuestas, la modernidad tiene dos momentos, el primero denominado la "temprana modernidad" o "primera modernidad", que como ya se dijo inicia desde el descubrimiento de América, resaltando que para ese momento Europa aún no se vuelve el centro geopolítico del sistema-mundo. Y el segundo, denominado "la hegemonía mundial de Europa" o "segunda modernidad", la cual da inicio con la Revolución Francesa y es cuando gracias a la caída del Este provoca que el Occidente (Europa) se convierta en el centro de la hegemonía mundial.

La evolución histórica del derecho será entendida desde este criterio histórico moderno, y, además, por ser parte de la modernidad también estará constituida por los vicios de ésta como: el universalismo abstracto y el eurocentrismo.

Como se señaló con anterioridad, "la primera modernidad" se preguntará ante la conquista de América: ¿Qué derecho tiene el europeo de ocupar, dominar, gestionar las culturas recientemente descubiertas, militarmente conquistadas y que están siendo colonizadas?, la respuesta será objeto de una gran producción teórica filosófica, destacando a Ginés de Sepúlveda y Fray Bartolomé de las Casas, además de Fray Alonso de la Veracruz y Francisco de Vitoria, entre otros. 
El resultado de estas controversias afectó el sentido del derecho, por eso no es extraño que el Derecho Indiano juega respecto de los nativos americanos o indios un doble rol: de protección y sometimiento.

Es de protección porque a partir de la Junta de Burgos (1512) se hace la reiteración de que "el indio es un ser libre con plenitud de derechos y capacidad". Esta declaración va en contra de los viejos principios del Derecho Medieval que considera a los "infieles salvajes" sin capacidad jurídica. Además, siguiendo a De la Torre Rangel:

Se prohíbe la esclavitud para los indios [...] Por otro lado, y ya aparece desde las Leyes de Burgos, se dictan normas de protección para los indios, tratando de contrarrestar la violencia y ambición de los conquistadores. Este Derecho proteccionista se basa en el principio de que, en justicia, se debe tratar desigual a los desiguales (De la Torre, Rangel, 2007:57).

Sin embargo, el Derecho Indiano también es de dominación porque si bien se consideraban a los indios como jurídicamente libres, existían otras disposiciones de derecho que colocan a los indios en un franco sometimiento, como la obligación de pagar tributos a la Corona derivada de la institución de la encomienda, que en muchas ocasiones convierte al indio en una especie de esclavo de hecho. Por lo anterior, coincidimos con Dussel cuando afirma que "América Latina quedará marcada por el legalismo perfecto en la teoría y por la injusticia y la inadecuación de la Ley en los hechos" (Dussel, 1972).

No obstante, cuando Europa se convierte en el centro geopolítico del sistemamundo fundamentado en la ideología de la ilustración, que posibilitará el pensamiento filosófico de la Revolución Francesa, y el romanticismo alemán, aunado a la consolidación de la Revolución industrial, el derecho es transformado amparando las nuevas prácticas de la ideología burguesa.

La burguesía triunfante, postula el reconocimiento de los "derechos naturales del individuo": libertad, seguridad jurídica y propiedad dentro de un régimen de igualdad ante la ley. En efecto:

Por igualdad se entiende- las "posibilidades legales, aunque no económicas para recibir educación, desempeñar cargos públicos, de contraer matrimonio, etc." (De la Torre, Rangel, 2006,)

Se constituye un reconocimiento común de ciudadanía ante la ley.

Por libertad se entiende- "que existe un derecho a trabajar sin sometimiento a normas gremiales; así como el contratar trabajo, entre patrón y obrero, en los términos de las voluntades "libres" que ambos convengan" (Ídem) En el terreno político la libertad adquiere el significado de "libertad de expresión". 
Por propiedad se entiende- "la medida de la capacidad individual de tener un poder excluyente sobre su persona y las cosas que pueda adquirir, ajustándose a las condiciones generales de la competencia por lo que habrá de ser libre, es decir no excluida por disposiciones restrictivas del mercado"(Ídem). El titular de la propiedad será el individuo que no reconocerá limitación alguna a su derecho, el cual se declara como "absoluto, sagrado e inviolable"

Por seguridad se entiende- la certeza en la eficacia de sus derechos como individuo.

Este derecho moderno, que se consolida con la Revolución Francesa, parte de una concepción individualista liberal del ser humano y de la sociedad. La burguesía, quien en un principio fue consolidándose por el crecimiento de la influencia de los mercados, siendo la sociedad feudal un obstáculo para su consolidación, lucha primero por sobrevivir y después por convertirse en clase hegemónica.

En el ámbito iusfilosófico, el derecho moderno se distancia de la Escuela del Derecho Clásico Cristiano, representando una tradición Iusnaturalista distintaiusnaturalismo moderno o racionalista- la cual es individualista y eminentemente racionalista. La Nueva Escuela del Derecho Natural cuya fundamentación filosófica será el Iusnaturalismo moderno, difundió la idea de los derechos subjetivos, que no existía en la tradición jurídico romana. Estos derechos subjetivos, comprendidos en el derecho a la libertad van alcanzar su máxima proclamación con el triunfo final de la burguesía, surgiendo así, en la Revolución Francesa perfectamente definido el sistema liberal individualista, fundamento del capitalismo moderno.

Para Jesús Antonio de la Torre Rangel, la Escuela del Derecho Natural obtiene tres resultados determinantes que caracterizarán al derecho moderno:

Primero: la igualdad de todos los hombres, al consagrar los derechos subjetivos desconocidos para el Derecho romano.

Segundo: la codificación del Derecho en normas generales, abstractas e impersonales, dictadas por el Estado legislador que llegará a identificar-con el positivismo del siglo XIX-Derecho con la Ley; vacía al Derecho, en consecuencia, de toda idea de justicia.

Tercero: la creación del derecho público paralelo al derecho privado, como garantizador de los derechos subjetivos y de igualdad formal, proclamados por el "Derecho Natural".

La modernidad insertará al Derecho su carácter de universalismo abstracto, ocasionando que el derecho moderno este formado por normas que tienen característica de ser generales, abstractas e impersonales.

Es general, porque se elabora para un número indefinido de personas y de actos o hechos, los cuales se aplican durante un tiempo indeterminado- universalismo abstracto en el sentido (a). La abstracción implica que el legislador al momento de crear la norma no tenga presentes los casos concretos a que vaya aplicarse la misma, y por 
consiguiente no parta de la realidad concreta material para su enunciación -el universalismo abstracto en sentido (b) - si no que parte del sujeto abstracto, vaciado de cuerpo y contenido al cual va aplicar la norma. Como consecuencia de la generalidad y abstracción, la norma es impersonal, ya que comprende a un número indefinido de personas a las cuales se aplica.

Finalmente, siguiendo a De la Torre, la concepción moderna del derecho es unívoca, debido a que ésta redujo al derecho a la ley que procede del Estado, por lo que se niega al pluralismo jurídico y la variedad de fuentes formales de derecho. "Derecho es igual a la ley del Estado y la ley del Estado es igual al derecho" (Ibidem:92).

\section{Ejemplo del Derecho Moderno en México}

Será el caso mexicano que tomaremos como ejemplo para analizar la penetración del individualismo liberal - uno de los pilares del Iusnaturalismo moderno- en América Hispana. Continuando con el Derecho Indiano, tras emerger en la "temprana edad moderna" e insertarse en el surgimiento y consolidación de la "hegemonía mundial de Europa", los nacientes Estados independientes liderados por las elites criollas, fueron introduciendo las corrientes liberales y los preceptos de la Escuela del Derecho Natural, dando paso a lo que Walter Mignolo, enuncia como la "doble conciencia criolla":

[...] Mignolo está convencido que el principio de doble conciencia es la característica del imaginario del mundo moderno-colonial desde las márgenes de los imperios. Para él, la emergencia del «hemisferio occidental» marcó la inserción de los criollos descendientes de europeos en el imaginario colonial [...] El criollo blanco afirmará su diferencia en relación a Europa en términos políticos o culturales más nunca fenotípicos [...] La especie dirigente es, antes que nada, la que viene de afuera, la que no se parece a los autóctonos, a los otros (Martínez, Andrade, 2009).

La "doble conciencia criolla" generada por los proyectos independentistas de principios del siglo XIX, e influenciados por la Ilustración europeizante, encuentra su proyección en el imaginario de la Otredad indígena, evaluada como minusválida y atrasada por las distintas elites - blancas o mestizas- en el poder.

Es así, como el Derecho Indiano será interpretado desde los preceptos de la Escuela del Derecho Natural, manifestándose en los nuevos ordenamientos elaborados por las elites emancipadas de origen criollo y mestizo, ya con las características de la juridicidad moderna: generalidad, abstracción e impersonalidad. 
En México, el triunfo definitivo del derecho moderno se logra con la promulgación de la Constitución de 1857, prototipo de ley fundamental de corte liberal, en donde se enuncia la igualdad ante la ley y la seguridad frente a la misma.

Para De la Torre Rangel, el liberalismo jurídico produjo en México:

Las leyes de desamortización; la constitución de 1857; aparejada a ésta, una interpretación individualista del Derecho por los tribunales; y las leyes sobre baldíos. Este Derecho privatizo la propiedad agraria, fueron funestas las consecuencias para las comunidades indígenas y los pequeños propietarios pobres. (De la Torre Rangel, 2006:88)

La ley de Desamortización, tenía como objetivo acabar con la acumulación excesiva de las tierras sobre todo por parte de las comunidades eclesiásticas y lograr así su circulación mercantil. Lo anterior se manifiesta en la ley expedida por el entonces presidente Ignacio Comonfort:

Todas las fincas rústicas y urbanas que hoy tienen o administran como propietarios las corporaciones civiles o eclesiásticas de la República, se adjudicarán en propiedad a los que las tienen arrendadas, por el valor correspondiente a la renta que en la actualidad pagan, calculada como rédito al seis por ciento anual [...] Bajo el nombre de corporaciones se comprenden todas las comunidades religiosas de ambos sexos, cofradías y archicofradías, congregaciones, hermandades, parroquias, ayuntamientos, colegios, y en general todo establecimiento o fundación que tenga el carácter de duración perpetua o indefinida[...] Desde ahora en adelante, ninguna corporación civil o eclesiástica, cualquiera que sea su carácter, denominación u objeto, tendrá capacidad legal para adquirir en propiedad o administrar por sí bienes raíces, con la única excepción que expresa el artículo 8o., respecto de los edificios destinados inmediatamente y directamente al servicio u objeto de la institución [...](Procuraduría Agraria, pp. 614-632)

No obstante, esta desamortización si bien toco los bienes eclesiásticos los cuales eran en suma excesivos, también toco a los ayuntamientos y a las comunidades indígenas, privándolas de personalidad jurídica. "La propiedad comunal indígena fue desamortizada con iguales procedimientos y los pueblos fueron despojados de sus antiguas propiedades" (De la Torre Rangel, 2006), terminando así la protección a las propiedades comunales de los pueblos que el Derecho Indiano les otorgaba.

La igualdad, la generalidad y la abstracción del derecho moderno quedaron definitivamente consagrados con la juridicidad individualista liberal mexicana. 


\section{El derecho desde la «exterioridad latinoamericana»}

La exterioridad, es una categoría que permite ajustar al derecho a la realidad latinoamericana. Esta puede ser definida como el ámbito desde donde el Otro ser humano, como libre e incondicionado a mi sistema y que no es parte de mi mundo, se revela.

Dussel piensa al Otro como originariamente lo piensa el filósofo lituano Emmanuel Lévinas. Sólo que para Dussel el Otro de Lévinas cae en lo equívoco y él propondrá al inequívocamente Otro 9

Lévinas entonces, propone pensar al Otro de la forma siguiente:

El Otro no es Otro con una alteridad relativa como, en una comparación, las especies, aunque sean últimas, se excluyen recíprocamente, pero se sitúan en la comunidad de un género, se excluyen por su definición [...] La alteridad del Otro no depende de una cualidad que lo distinguiría del yo [...] Y sin embargo, el Otro no niega pura y simplemente el Yo: la negación total, cuyo intento y tentación es el asesinato, remite a una relación previa[...] El Otro permanece infinitamente trascendente, infinitamente extranjero, pero su rostro, en el que se produce su epifanía y que me llama, rompe con el mundo que puede sernos común[...] (Lévinas, 2002:207-208).

Para Dussel, la exterioridad al igual que Lévinas, es permanecer infinitamente trascendente al Otro, es una metáfora espacial, el ser humano en cualquier sistemamundo del Otro es siempre trascendental, está más allá del ser, más allá de la comprensión de mi mundo, porque yo no tengo la totalidad de las experiencias del mundo del Otro, sería imposible, por eso es infinitamente extranjero. El Otro es la alteridad de todo sistema posible, más allá de lo "mismo" que la totalidad es.

Desde esa totalidad capitalista del sistema-mundo hegemónico, cuyo fundamento es el valor que se valoriza, se niega la alteridad del Otro tomando su exterioridad para incorporarlo a la totalidad dominante (subsumirlo) como mediación. El Otro deja de ser Otro y es subsumido en "lo mismo", pasando a ser un "ente" al que puedo dominar o explotar. La totalización de la exterioridad es la expansión dialéctica-

9 Lévinas habla siempre del Otro como "absolutamente Otro", tiende entonces hacia la equivocidad. Por otra parte, nunca ha pensado que el Otro pudiera ser el indio, un africano, un asiático. El otro, para nosotros, es América Latina con respecto a la totalidad europea; es el pueblo pobre y oprimido latinoamericano con respecto a las oligarquías dominadoras y sin embargo dependientes. (Véase, De la Torre Rangel, 2001: 89). 
dominadora de lo "mismo", que "asesina" al Otro y lo totaliza en lo "mismo", es decir, lo subsume ${ }^{10}$ en lo "mismo" que es la identidad del sistema.

Por ejemplo, la existencia del pobre o del indígena, pensada desde la totalidad dominante, sólo puede explicarse como parte de una totalidad a la que no han sido capaces de integrarse adecuadamente, son diferentes de la clase dominante y el sistema da por natural la existencia de ellos. En cambio, sí privilegiamos el pensamiento desde la exterioridad latinoamericana, veremos que los rostros de ambos aparecen ajenos a esa totalidad, pues poseen una especificidad radical, que, como tal, no pueden hacer más que poner en cuestión al sistema que los excluye e introducir la novedad para crear una totalidad radicalmente nueva.

Por consiguiente, pensar desde la exterioridad implica un compromiso abierto e inmediato a favor de aquel que con su palabra o con el gesto significante nos interpela y nos llama asumir el compromiso ético que permita ser Otro al Otro, de lo anterior se desprende una Ética de la Alteridad, basada en la responsabilidad que tengo por el Otro y la conducta que le es debida, pues la relación entre el Yo viviente y el Otro, es el nexo fundante de la justicia.

Dussel nos señala ya los pasos en su obra la ética de la liberación:

Primero: oír la voz del Otro, para ello se requiere de ser ateos del sistema (descubrir su fetichismo) y respetar al Otro como Otro, como es lo único sagrado y digno de respeto sin límite.

Segundo: hacerse cargo del Otro, hacerse responsable. Se expone al hombre justo a los ataques del sistema, que se siente atacado por su apertura, exposición y gratuidad. Es visto como el destructor del orden.

Tercero: praxis de liberación. Aquí ya la acción liberadora se dirige al Otro, simultánea de un trabajo a su favor (Dussel, 2011:68).

Ese saber oir, deviene necesariamente en un saber interpretar, mismo que no se reduce a una mera contemplación teórica sobre el Otro como víctima, pobre o excluido, sino que significa la irrupción de una praxis de liberación que, como tal, trata de modificar las condiciones generales de la opresión, es también un saber servir.

Hasta aquí, podemos dar respuesta a lo que significa pensar al derecho desde la exterioridad y por qué desde la exterioridad latinoamericana.

10 Subsumir, es una categoría de la Filosofía de la Liberación de Dussel y significa la negación que hace el sistema de la corporalidad del ser humano y lo incorpora a este como mediación de su fundamento, Dentro de la subsunción se encuentra la alienación, es un momento de éste. 
Como ya habíamos mencionado en la introducción, pensar al derecho desde la exterioridad posibilita enfrentar a los problemas de la modernidad desde un marco categorial distinto al moderno, una revalorización de las epistemologías que son exteriores a la totalidad como el pluralismo jurídico - superando al universalismo en sentido (a)- que transgreda a la totalidad dominante, comprometiendo al derecho con los procesos liberadores y con el pleno reconocimiento de la alteridad del Otro, de la justicia y del derecho a la vida con dignidad, es decir, corporalizando al sujeto que es el inequívocamente Otro- superando el universalismo en sentido (b).

Si partimos de esta fundamentación propuesta, descubriremos que el Otro -sujeto del derecho- no es ya un "yo" cerrado (ego cartesiano) sino más bien un "yo abierto". En este contexto como nos lo marca el Doctor Rosillo (Rosillo Martínez, 2013), la subjetividad moderna (ego cartesiano) es parte de la totalidad que sólo reconoce derechos a los mismos, no al inequívocamente Otro al que la totalidad considera extraño, ajeno y hasta peligroso para el sistema. Ese Otro, aunque exija las mismas necesidades de los mismos es catalogado de delincuente; por eso se criminalizan las protestas y las luchas sociales, por eso las praxis de liberación se reprimen.

Pensar la exterioridad desde América latina, permite corporalizar al sujeto de la acción, partiendo de un sujeto histórico, material y concreto, posibilitando enunciar al derecho desde las victimas del sistema, desde el inequívocamente Otro, es decir, desde los indígenas, negros, mujeres, obreros, campesinos, ancianos, etc., desde todo aquel que gracias a las condiciones materiales de nuestros pueblos le son negados su producción, reproducción y desarrollo de vida en comunidad. A este Otro, que en justicia se le deben cosas y conductas, se le debe su derecho, y entre el Otro, y el inequívocamente Otro -persona negada, la víctima del sistema-mundo- existen iguales derechos comunes en su reconocimiento, pero en donde al inequívocamente Otro le son negados en la eficacia histórica de esos derechos.

\section{Conclusión}

Como vimos, la filosofía de la modernidad ha contribuido a la constitución y reproducción de la universalidad abstracta y a la des-corporalización del sujeto epistémico desde donde se enuncia la realidad. Siendo por consiguiente eurocéntrica, pues la cultura, civilización, filosofía y subjetividad de la modernidad europea fueron tomadas como lo humano universal. Por consiguiente, el pensamiento de la modernidad dotó al derecho su carácter de universalismo abstracto, ocasionando que el Derecho moderno este formado por normas que tienen característica de ser generales, abstractas e impersonales.

Por lo anterior, presentamos una crítica al Derecho moderno desde la exterioridad, la cual posibilita pensar al derecho desde un locus epistemológico adecuado a la realidad latinoamericana. Dando paso a una revalorización de las epistemologías que 
son exteriores a la totalidad como el pluralismo jurídico, y a un compromiso por parte del derecho con los procesos liberadores y con el pleno reconocimiento de la alteridad del Otro, de la justicia y del derecho a la vida con dignidad, es decir, con la corporalización del sujeto - un sujeto histórico, concreto y material- pensando al derecho desde el inequívocamente Otro. 


\section{Bibliografía}

ARTuro, E. (2003) Mundos y conocimientos de otro modo. El programa de investigación de modernidad/colonialidad latinoamericano. Tabula Rasa, (1), pp. 5186.

DE LAS CASAS, B. (2016). Brevísima relación de la destrucción de las Indias. Recuperado de http://aix1.uottawa.ca/ ${ }^{\text {jmruano/relacion.pdf }}$

CAStro-Gómez, S. (2005). La poscolonialidad explicada a los niños, Colombia, Editorial Universidad del Cauca.

De la Torre Rangel, J.(2007). El uso alternativo del derecho por Bartolomé de las Casas, San Luis Potosí, CEDH, UASLP, CENEJUS, CRT.

(2001). Derechos Humanos desde el Iusnaturalismo Histórico Analógico, México, Porrúa.

(2006). El derecho como arma de liberación en América Latina, San Luis Potosí, UASLP, CENEJUS, CEDH.

Dussel, E. (2000). Europe, Modernity, and Eurocentrism. Nepantla.

(2004). "Sistema-mundo y transmodernidad" en Modernidades coloniales, México, El Colegio de México.

(1994). El encubrimiento del indio: 1492. Hacia el origen del mito de la modernidad, México, Cambio XXI.

(1998) Ética de la liberación en la edad de la globalización y de la exclusión, Madrid, Trotta. 
(1972). Historia de la Iglesia en América Latina, Barcelona, Nova Terra. (2011). Filosofía de la Liberación, México, FCE.

Grosfoguel, R. (2008). Hacia un pluriversalismo transmoderno decolonial. Tabula Rasa. Buenos Aires.

Houtart, FrançoIs (2015). El bien común de la humanidad, San Luis Potosí, UASLP-CENEJUS-Mispat.

KANT, I.L (2004). Antropología, Madrid, Alianza Editorial.

LÉVINAS, E. (2002). Totalidad e infinito. Ensayo sobre la exterioridad, Salamanca, Ediciones sígueme.

-2009). Humanismo del otro hombre, México, XXI.

MALDONADO TORRES, N. (2009). "El pensamiento filosófico del giro descolonizador”. In: Dussel Enrique, Mendieta, et al., (Coord), El pensamiento filosófico latinoamericano, del Caribe y latino [1300-2000], México, Siglo XXI, CREFAL.

MARTíNEZ ANDRADE, L. (2016). "La reconfiguración de la colonialidad del poder y la construcción del Estado-nación en América Latina”, en Amérique Latine Histoire et Mémoire. Les Cahiers ALHIM. Recuperado de http://alhim.revues.org/2878

Procuraduría Agraria (2016). Ley de Desamortización de Bienes de Manos Muertas. Recuperado de http://www.pa.gob.mx/publica/MARCO\%20LEGAL\%20PDF/LEY\%20DESAM\%2 OBIE\%20MAN\%20MUER.pdf

Quijano, Aníbal, (2014) "Colonialidad del poder y clasificación social" en Cuestiones y horizontes: de la dependencia histórico-estructural a la colonialidad/descolonialidad del poder, Buenos Aires, CLACSO. 
Robles, Fernando (2012) "Epistemologías de la Modernidad: entre el etnocentrismo, el racionalismo universalista y las alternativas latinoamericanas". Cinta de Moebio, (45).

Rosillo Martínez, Alejandro (2013). Fundamentación de derechos humanos desde América Latina, México, ITACA.

Salamanca Serrano, Antonio (2011). Teoría socialista del Derecho (Iusmaterialismo). Tomo II, Ecuador, Editorial Jurídica del Ecuador.

BOAVENTURA, SOUSA SANTOS (2005). El milenio del huérfano. Ensayos para una nueva cultura politica, Madrid, Trotta.

(2011). Epistemologías del Sur, Madrid, Trotta.

WolKMER CARlos, ANTONIO (2006). Introducción al pensamiento jurídico crítico, San Luis Potosí, UASLP, CEDHSLP, ILSA. 